\title{
Métodos para a Avaliação de Riscos Laborais- Método de Falhas e Efeitos
}

Santos M, Almeida A, Lopes C, Oliveira T. Métodos para a Avaliação de Riscos Laborais- Método de Falhas e Efeitos. Revista Portuguesa de Saúde Ocupacional on line. 2019, volume 8, 1-3. DOI; 10.31252/RPSO.19.07.2019

TIPO DE ARTIGO: Artigos da Equipa Técnica

Autores: Santos M(1), Almeida A(2), Lopes C(3), Oliveira T(4).

Esta metodologia usa-se sobretudo para equipamentos/ instrumentos, de forma a assinalar as eventuais consequências de possíveis falhas. Primeiro define-se o sistema, incluindo uma enumeração dos componentes e equipamentos, assinalando também todas as falhas que possam ocorrer, não esquecendo a etiologia e consequências possíveis. Posteriormente incide-se no que se poderá fazer para atenuar a incidência e gravidade dessas situações.

Torna-se pertinente construir escalas de gravidade e probabilidade. A primeira poderá se regular pela estratificação registada no quadro 1.

Quadro 1: Níveis de Gravidade

\begin{tabular}{ll} 
Níveis & Significado \\
\hline $\mathbf{1}$ & Desprezível \\
\hline $\mathbf{2}$ & Danos ligeiros na instalação \\
\hline $\mathbf{3}$ & Danos importantes nas instalações locais \\
\hline $\mathbf{4}$ & Danos graves nas instalações locais \\
\hline $\mathbf{5}$ & Danos graves na empresa \\
\hline $\mathbf{6}$ & Danos graves para além dos limites da empresa
\end{tabular}

Por sua vez, a Nível de Probabilidade poderemos considerar os dados inseridos no quadro 2.

Quadro 2: Níveis de Probabilidade

\begin{tabular}{ll} 
Nível & Significado \\
\hline $\mathbf{1}$ & Extremamente baixa \\
\hline $\mathbf{2}$ & Frequência reduzida \\
\hline $\mathbf{3}$ & Pouco frequente \\
\hline $\mathbf{4}$ & Bastante possível \\
\hline $\mathbf{5}$ & Frequente \\
\hline $\mathbf{6}$ & Muito frequente
\end{tabular}

A avaliação de risco variará entre 11 e 66, colocando nas abcissas a gravidade e no eixo das ordenadas a probabilidade (ver quadro 3).

Quadro 3: Avaliação de Risco

\begin{tabular}{llllll}
16 & 26 & 36 & 45 & 56 & 66 \\
\hline 15 & 25 & 35 & 45 & 55 & 65 \\
\hline 14 & 24 & 34 & 44 & 54 & 64 \\
\hline 13 & 23 & 33 & 43 & 53 & 63 \\
\hline 12 & 22 & 32 & 42 & 52 & 62
\end{tabular}


$\begin{array}{llllll}11 & 21 & 31 & 41 & 51 & 61\end{array}$

Aqui o vermelho representa risco muito elevado: as falhas neste patamar devem ser totalmente eliminadas; por sua vez, o laranja representa um risco alto: as falhas aqui inseridas devem ser reduzidas até patamares aceitáveis e o amarelo simboliza um risco médio.

Um exemplo de tabela final para registo deste método poderá ser visualizada no quadro 4.

Quadro 4: Exemplo de tabela de registo para o método de Falhas e Efeitos

\begin{tabular}{lcccc}
$\begin{array}{l}\text { Componentes do } \\
\text { subsistema }\end{array}$ & Efeitos da falha & $\begin{array}{l}\text { Compensações/ Gravidade Probabilidade Magnitude } \\
\text { procedimentos }\end{array}$ & $\begin{array}{l}\text { Ordem } \\
\text { Recomendações/ } \\
\text { observações }\end{array}$ \\
\cline { 1 - 1 } $\begin{array}{l}\text { Nome/ Falha Causas Local } \\
\text { referência }\end{array}$ & $\begin{array}{l}\text { No } \\
\text { sistema }\end{array}$ & \\
\hline
\end{tabular}

\section{BIBLIOGRAFIA GERAL}

(usada na elaboração de todos os artigos relativos a métodos para avaliação dos riscos)

1-Pedro R. Métodos de Avaliação e Identificação de Riscos nos locais de Trabalho. Tecnometal. 2006, 167, 1-8.

2- Mendonça A. Métodos de Avaliação de Riscos- contributo para a sua aplicabilidade no setor da Construção Civil. Relatório de Atividade Profissional para a obtenção do Grau de Mestre em Engenharia do Ambiente. Faculdade de Ciência e Tecnologia, Universidade do Algarve. 2013, 1-225.

3-Batista J. Adaptação de Métodos Matriciais para a Avaliação de Riscos Profissionais. Safemed. 2016, 1-22.

\section{(1)Mónica Santos}

Licenciada em Medicina; Especialista em Medicina Geral e Familiar; Mestre em Ciências do Desporto; Especialista em Medicina do Trabalho e Doutoranda em Segurança e Saúde Ocupacionais, na Faculdade de Engenharia da Universidade do Porto.

Presentemente a exercer nas empresas Medicisforma, Servinecra, Securilabor, Medimarco e Tradsafety; Diretora Clínica das empresas Quercia; Diretora da Revista Portuguesa de Saúde Ocupacional on line. Endereços para correspondência: Rua Agostinho Fernando Oliveira Guedes, 42, 4420-009 Gondomar. E-mail: s_monica_santos@hotmail.com.

\section{(2) Armando Almeida}

Doutorado em Enfermagem; Mestre em Enfermagem Avançada; Especialista em Enfermagem Comunitária; Pós-graduado em Supervisão Clínica e em Sistemas de Informação em Enfermagem; Docente na Escola de Enfermagem (Porto), Instituto da Ciências da Saúde da Universidade Católica Portuguesa; Diretor Adjunto da Revista Portuguesa de Saúde Ocupacional on line. 4420-009 Gondomar. E-mail: aalmeida@porto.ucp.pt.

\section{(3) Catarina Lopes}

Licenciada em Enfermagem, desde 2010, pela Escola Superior de Saúde Vale do Ave. A exercer funções na área da Saúde Ocupacional desde 2011 como Enfermeira do trabalho autorizada pela Direção Geral de Saúde, tendo sido a responsável pela gestão do departamento de Saúde Ocupacional de uma empresa prestadora de serviços externos durante 7 anos. Atualmente acumula funções como Enfermeira de Saúde Ocupacional e exerce como Enfermeira Generalista na SNS24. Encontra-se a frequentar o curso Técnico Superior de Segurança do Trabalho.4715-028. Braga. E-mail: catarinafflopes@gmail.com

\section{(4)Tiago Oliveira}

Licenciado em Enfermagem pela Universidade Católica Portuguesa. Frequenta o curso de Técnico Superior de Segurança no Trabalho. Atualmente exerce a tempo inteiro como Enfermeiro do Trabalho. No âmbito desportivo desenvolveu competências no exercício de funções de Coordenador Comercial na empresa Academia Fitness Center, assim como de Enfermeiro pelo clube de futebol União Desportiva Valonguense. 4435-718 Baguim do Monte. E-mail: tiago_sc16@hotmail.com. 